\title{
UNDERSTANDING SHARED SERVICES (Article 1 of 3)
}

\author{
TN van der Linde, AL Boessenkool \& CJ Jooste, University of Johannesburg
}

\begin{abstract}
Purpose: Shared services is a viable business model that can be used by organisations to reduce costs and enhance efficiency and effectiveness in the organisation. The purpose of this trilogy of articles is to introduce shared services as a business model, and how to efficiently and effectively manage a shared services business unit.
\end{abstract}

The purpose of the first article in the trilogy, introduces shared services as a business model, defines what shared services is, the transformation required to successfully implement a shared services business model, as well as the benefits that can be derived from implementing a shared services business model.

Methodology: A comprehensive literature study was conducted in order to:

- Define and describe shared services as a business model,

- Compare shared services with centralisation and de-centralisation,

- Determine and describe the transformation required to successfully implement shared services.

Findings: In the article, a framework is generated to help organisations understand the business concept of shared services. This work has further potential: when applied correctly, there are both tangible and intangible benefits that can be accrued above cost savings.

Implications: The findings of this article are important for organisations that are in the process of implementing or have implemented shared services, as it will assist the organisation in determining if shared services is the correct business model for them to implement.

Value: This article provides an understanding of shared services and the business environment required to successfully implement a shared services business model. Value created by a shared services business model is further enhanced once the organisation has embarked on the successful implementation of a shared services business model, which is the primary objective of the second article, Implementation and continuous evolution in shared services.

Key words and phrases: Shared services, centralisation, de-centralisation, benefits, transformation.

\section{INTRODUCTION}

Local and global competition necessitates continuous improvement in business processes. Technology enables organisations to take advantage of knowledge. Knowledge management (KM) provides organisations with core competencies. Teams are replacing command and control hierarchies. Time honoured strategies such as decentralisation or centralisation without improving work processes, or technology solutions without standardised source data, will no longer work. Gunn, Carberry, Frigo and Behrens (1993:22), are of the opinion that "Shared services" is a new management concept for addressing these issues". Sun Microsystems implemented a shared services business model "not because of any problem today but to avoid problems in the future" (Quinn, Cooke \& Kris, 2000:215). The following discussion starts a shared services journey, because deciding on and implementing a shared services business unit is not the end of the shared services business model. This first step of the journey will only provide an overview of what this "new management concept" of shared services is, and how it provides value to the organisation and all the stakeholders involved.

\section{PROBLEM STATEMENT AND RESEARCH METHODOLOGY}

Organisations are implementing shared services as a business model to gain cost advantages (Mohan, 2006:14). These cost advantages can be obtained through (mostly) a reduction in staff cost, business process re-engineering (seen as staff retrenchment), the effective and efficient use of 
technology, and increased productivity. This is also the premise on which business consultants are selling the shared services concepts as a business model (we can save the organisation money by reducing cost). But this selling point also provides the basis of negative perceptions that shared services is just another word for "staff retrenchment" and/or "centralisation". But shared services is more than just cost savings through a reduction in staff numbers; shared services is a business model that can provide organisations with a sustainable competitive advantage. Organisations, through business consultants, are implementing shared services without fully understanding what shared services really is and what is required to successfully implement and manage a shared services business unit.

The primary goal of the series of articles is to explain the concept of shared services, how do you implement a shared services business model and, after implementation, how do you manage a shared services business unit. This will be sufficient if it satisfies the sub-goals:

- Determine through a literature study the body of knowledge surrounding the concept of what shared services is, and what it is not (Article one of three).

- After understanding the concept of shared services, what are the stages an organisation needs to go through to successfully implement a shared services business unit (Article two of three).

- Through a literature and empirical study, determine the key success factors required to successfully manage a shared services business unit (Article three).

The study is qualitative in nature. The research design of the study is exploratory. Secondary data analysis provides the theoretical background to the study. Unstructured interviews guided by an interview schedule on the sample elements provided the primary data for the study. Judgment and snowball sampling techniques were used to identify the sample elements.

\section{SHARED SERVICES DEFINED}

Schulman, Harmer Dunleavy and Lusk (1999:9) defined shared services as "the concentration of organisational resources performing like activities, typically spread across the organisation, in order to serve multiple internal partners at lower cost and with higher service levels, with the common goal of delighting external customers and enhancing corporate value."

With production processes streamlined to ensure cost savings, organisations are looking at "back office" operations, or "support services" to gain further cost savings. Kaplan and Norton (1996:175) are of the opinion that support processes such as finance, human resources and others are not subjected to market tests and as such often end up as a "source of disadvantage". Through shared services, this "source of disadvantage" can be turned into an income generating business unit. According to Quinn et al. (2000:3), organisations require more accessible services for less cost, and the authors consequently provide a working definition of shared services as "... the relatively simple practise of deciding to share common services between a group of companies, divisions or business units". This decision to share common services between a group of companies and/or divisions is graphically presented in Figure 1.

Figure 1 represents organisation A with three divisions, of which the core businesses are design, manufacturing and marketing respectively. The three divisions are located in different geographical areas. Finance has been established as a shared services business unit performing the finance and accounting function for all three divisions. Common processes that can also be established as possible shared services business units are human resources and information technology. In this particular example, the shared services business unit is located in another geographical area indicating one of the characteristics of shared services, namely that shared services doesn't equate to centralisation. 


\section{Figure 1: Shared Services}

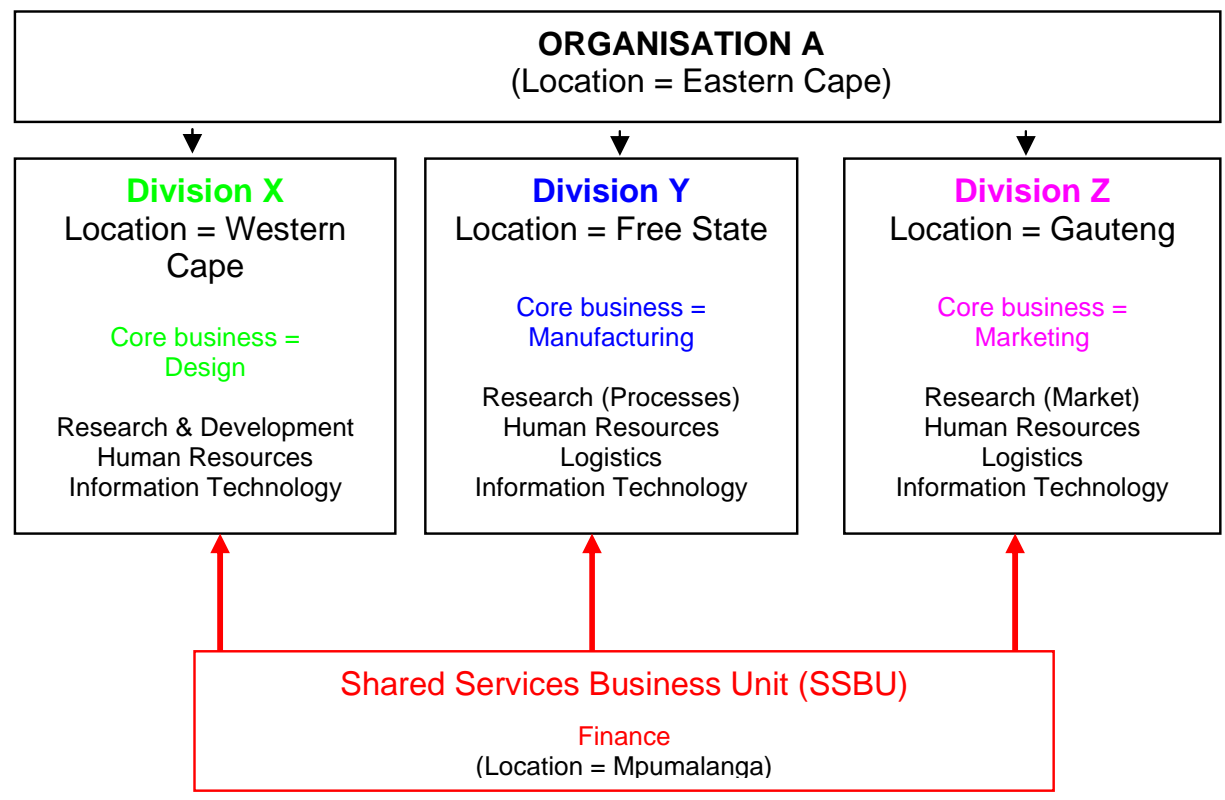

\section{Source: Author derived}

Along the generic value chain, shared services can be presented as in Figure 2. In Figure 2, the support activities in a single organisation are extended across organisations, multiple companies, divisions or business units. In Figure 2, the support activities of human resource management and finance have been transformed through shared services into a primary activity, and even into a separate business unit from where the service is provided. According to Deloitte Consulting (2004:11), the secondary functions that were transformed into shared services included:

- Finance $89 \%$

- Human resources $70 \%$

- Supply chain $53 \%$

- Administration $44 \%$, and

- Information technology $42 \%$.

According to Porter (1985:325), the lowest level of sharing can be activities such as "benefit administration" in the human resources function. In the secondary activity of finance, the activity of accounts payable constitutes $83 \%$, and benefit administration $35 \%$ in the human resources function (Deloitte Consulting, 2004:11). This might create the impression that the sharing (shared services) of these activities is "centralisation" in disguise.

A word of caution is required at this stage. According to Quinn et al. (2000:14), organisations should consider shared services before outsourcing the activity or function. Outsourcing only becomes an option if an activity or function can be performed at a lower cost and higher service level than if performed by the organisation itself. Shared services provides an organisation with an opportunity to provide the activity or function at a lower cost and with higher service levels than currently provided in the organisation. Shared services also allows for the organisation to keep expertise in-house. For shared services to establish itself and grow, a grace period of two to four years is often required, during which internal customers must be prohibited from using other service providers. During such a period, internal customers who are not satisfied with the service level and associated costs may be free to seek better prices and services from outside service providers (Van Denburgh \& Cagna, 2000:5). 


\section{Figure 2: A Shared Services Value Chain}

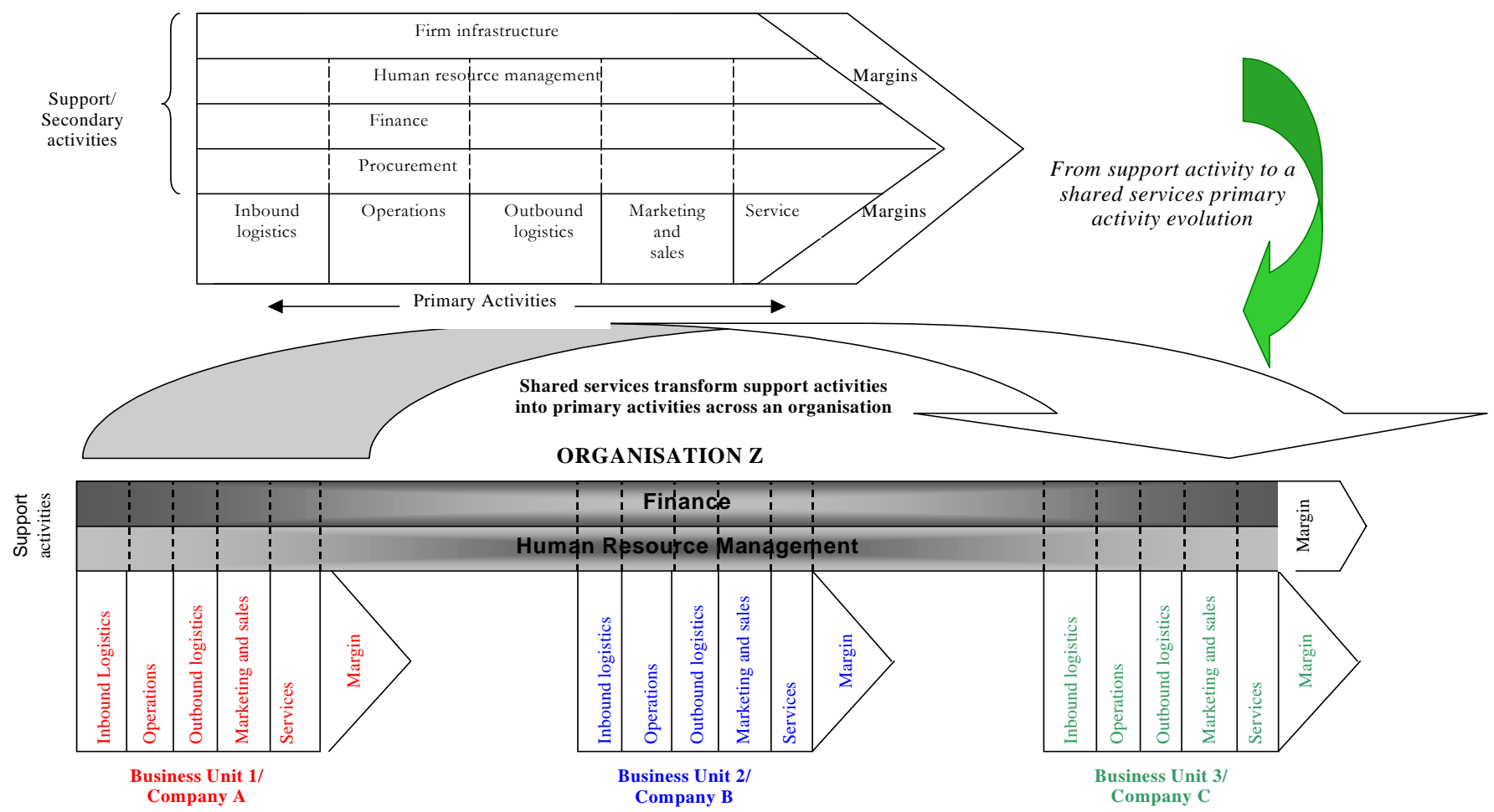

Source: adapted from Porter (1985:37)

\section{CENTRALISATION, DECENTRALISATION OR SHARED SERVICES}

According to Del Rosario (2001:4), shared services "is anything but centralisation". The idea of shared services is to share resources - organisational staff and technology - while providing defined services (as defined in the service level agreement - SLA) at a cost and service level that exceed the requirements of the internal customer. This is facilitated by the rapid advances in information technology (IT), software development and, more specifically, the developments in enterprise resource planning (ERP) software.

Shared services is neither "centralisation" nor "decentralisation", but incorporates elements of both. Figure 3 indicates which elements of centralisation and decentralisation are incorporated into a shared services business environment.

In a centralised organisation, the focus of the business units and back office support operations is upwards and towards the corporate headquarters. Centralisation brings with it unresponsive, inflexible and costly business units. Decentralisation is associated with duplication of effort, higher costs and variable standards. By contrast, shared services is outward-orientated towards the business units it serves, is an equal partner in the organisation, and is responsible for its own costs and service levels. Shared services enhances decentralisation as it allows each business unit to focus on the strategic part of its operations and allocate the support services to another party. In effect, operational business units and organisations "outsource" these transactional services to an internal third party. Schulman et al. (1999:13) refer to this concept as "insourcing". This leads to two questions: "what is shared services?" and "what is shared services not?" 
Figure 3: Elements of centralisation, decentralisation and shared services

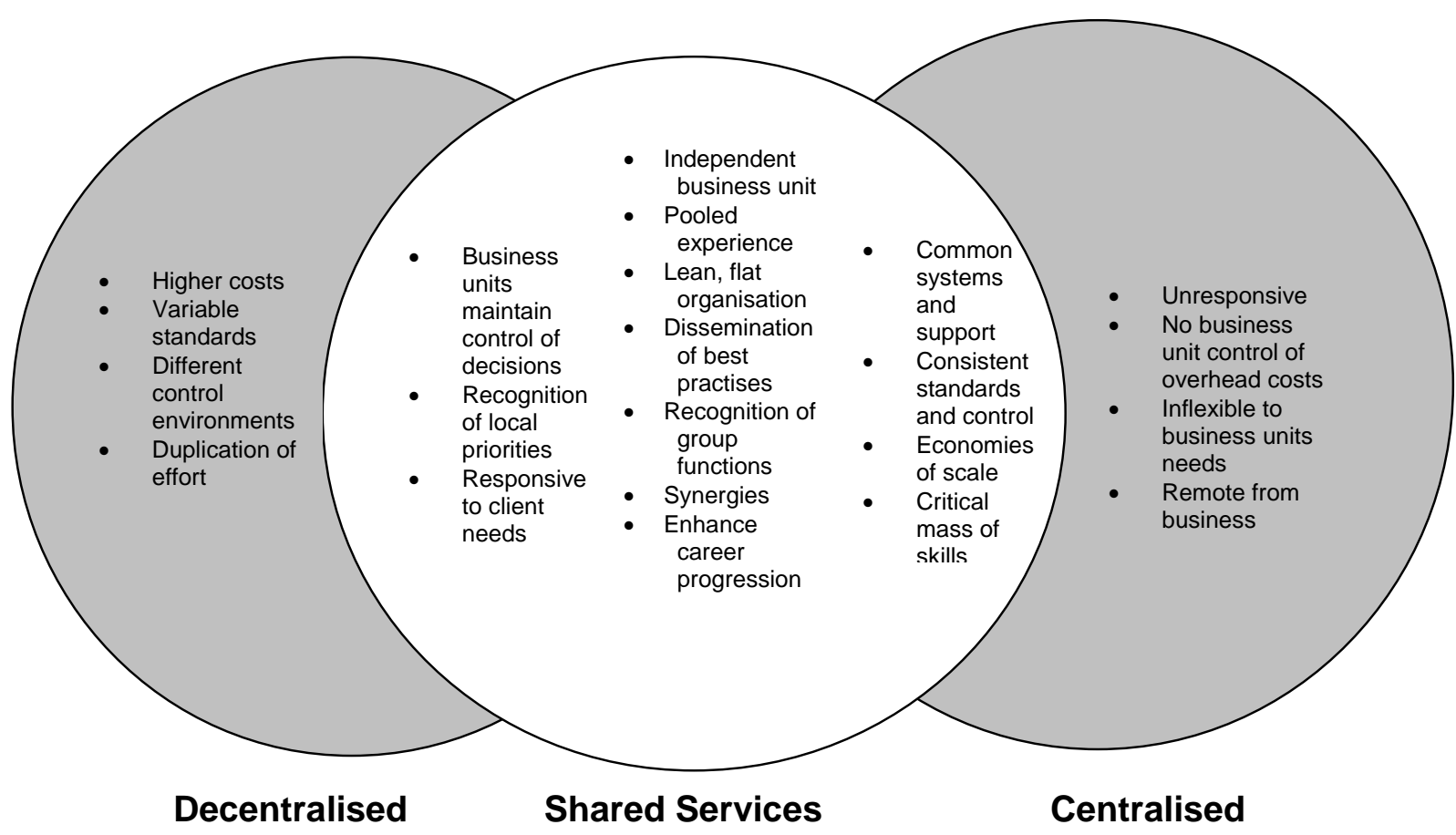

Source: adapted from Schulman et al. (1999:12)

\section{WHAT IS SHARED SERVICES?}

Based on the formal and working definition of shared services and statements made by Deloitte Consulting (2000:2-4), the following points emerge:

- Shared services is "commonised" support processes and systems to provide a better service to operational units. According to Van Denburgh and Cagna (2000:2), sixty to seventy percent of an organisation's activities can be standardised, with the remaining portion requiring customisation. This implies that business support processes should be the same across operational units.

- Shared services is focussed on internal customer satisfaction, continuous improvement and best practises. Del Rosario (2001:3) describes it as "a focus on standardised best-practise processes".

- Shared services emphasises value creation. With sixty to seventy percent standardised transactions and the remainder requiring "customisation", shared services continuously redesigns and re-engineers business processes to create greater efficiency and effectiveness and, as such, added value.

- Shared services is a separate business unit. As a separate business unit, shared services must provide a better than perceived service, and not just the bare minimum (SLA). It should not be a cost centre that recovers its cost via "charge outs", as there is then no motivation for improving service levels. According to Schulman et al. (1999:31), Lucent Technologies gained acceptance of shared services through their approach stating that "it's a business mindset". A business mindset for shared services requires that:

o It is a business - Run it like a business! Shared services therefore requires: 
- A strategic plan.

- Delivery channels/cycle time.

- A product plan and offerings.

- Key measures and metrics.

- Continuous benchmarking.

o Exceedingly efficient and effective partner service.

o On time, at cost, at quality, ahead of competition.

o Results focused, NOT activities.

o Line of sight to the customer.

o Driving the top line.

- Showcase of company products.

o Focused on the entire value chain.

- Shared services is a high volume, low cost transactional service provider. Through the consolidation of back-office operations and business process re-engineering, greater economies of scale can be obtained.

- Shared services has a high degree of specialisation. Freeing "professionals" from transactional activities allows them to concentrate on more specialised technical areas (Shah, 1998:3). These specialised services are also referred to as "centres of excellence" (Uhlrich, 1995:4).

- Shared services leverages the skills and knowledge base in an organisation. Individual business units might not be able to afford the services of specialists. Shared services can afford these specialists because of their larger clientele base, and offer these services to other business units (Shah, 1998:3). According to Quinn et al. (2000:110), these specialists protect the overall assets of the organisation through their enterprise-wide focus, instead of meeting individual clients' needs. Figure 4 indicates how specialist services are directed upwards towards the top executive team and Board, while spanning the organisation.

- Shared services is customer and process focussed. A shared services business unit domain may not be situated in a "head office", or for that matter in any office of the organisation. It may even be of a virtual nature. Regardless of its nature or domain, it is focussed to work in a processorientated manner while meeting customer requirements and needs (Shah, 1998:3).

- Shared services uses leading edge enabling technology. Technology is the platform that makes shared services possible. Business units on their own may not be able to afford this leading edge enabling technology, but by pooling resources, the cost of enterprise-wide software such as SAP, Oracle and others can be justified.

- Shared services is a process of continuous improvement. Shared services allows an organisation to focus on operational excellence. According to Shah (1998:4), it is much easier to drive change and improvement in a single location with forty people than fifteen locations with six people each.

- Shared services continuously benchmarks its processes. Shared services can continuously benchmark itself against the "best in business" and improve the quality of the transactions and services offered by utilising best practises and continuous re-engineering (Schulman et al., 1999:177). 


\section{Figure 4: Shared services directed at specialist functions}

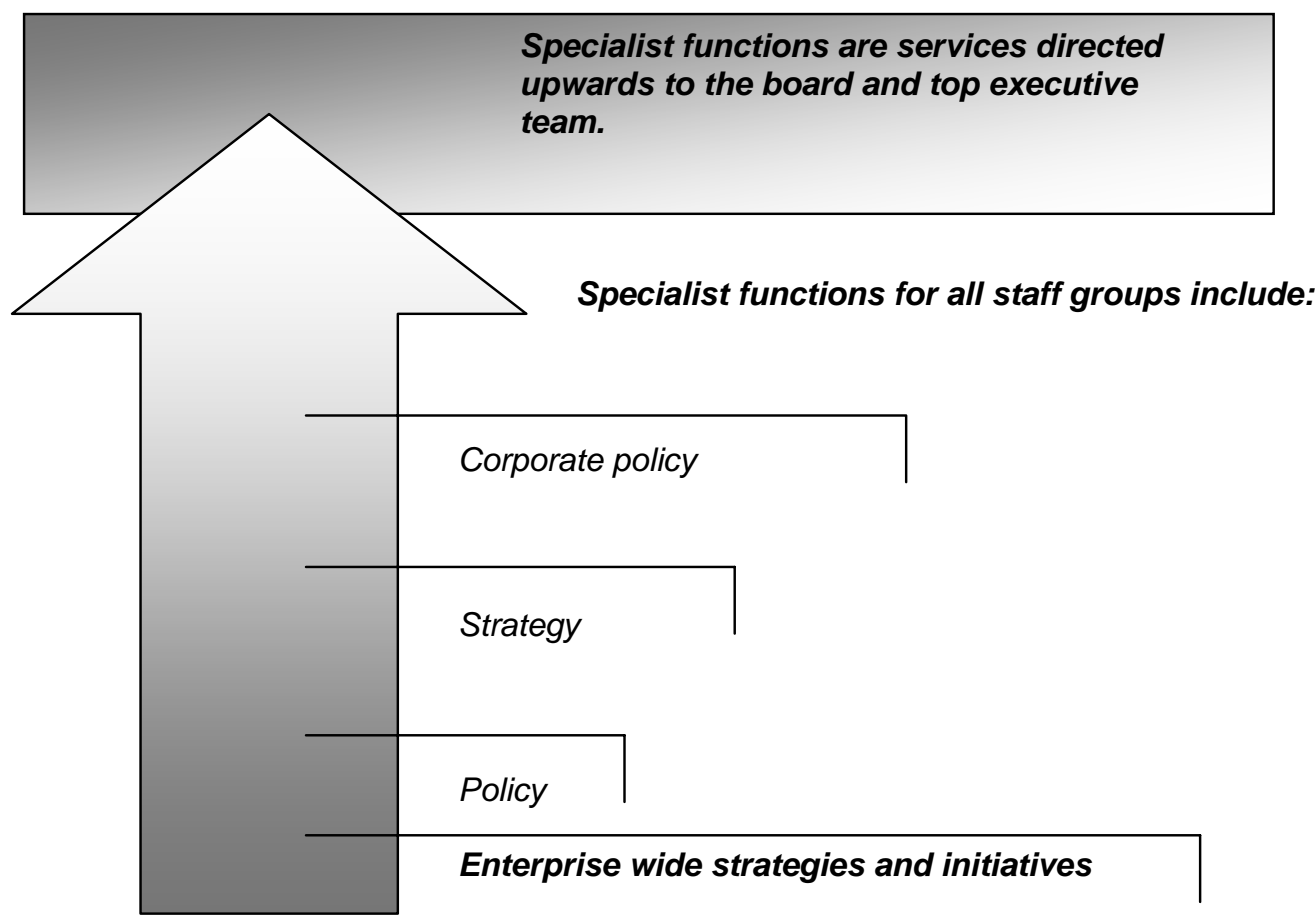

Source: adapted from Quinn et al. (2000:110)

- Shared services employees' rewards and incentives are performance based. A shared services business unit can have its own reward, compensation and incentive system that differs from that of the larger organisation (Shah, 1998:3). These incentives can be team orientated and focussed on key performance measures or on value added.

- Shared services provides high quality and best practice service standards through the use of performance measurement. A service level agreement (SLA) between the shared services business unit and its (internal) customers determines the minimum service level required. A performance measurement system will determine its performance targets and systems to report on how well (or not) the shared services business unit is performing with its customers in creating and delivering value (Shah, 1998:3).

\section{WHAT IS SHARED SERVICES NOT?}

As shared services is constantly changing through continuous improvement and evolution, there are some misconceptions about what shared services is. Some of these misconceptions are clarified below:

- Shared services is not "centralisation", even though business processes are "commonised".

- Shared services is not a simple cost reduction measure that is achieved through process consolidation and process elimination (Shah, 1998:2). If processes are consolidated with the only purpose to save costs and not add value and empower employees (team members), it is not shared services but rather centralisation.

- Shared services is not an internal push to have all support (non-core) activities and business processes performed by outside service providers. If outside service providers supply the support activities, it is "outsourcing". Both "outsourcing" and "insourcing" takes a dispersed set of activities 
and consolidate them into a centralised processing environment. Both place activities in the hands of experts who can apply innovative technologies and knowledge to provide service solutions. Where outsourcing assigns the work to an outside third party, shared services enables an organisation to keep its expertise in-house and build upon the skills, knowledge and experience already in place. With shared services, organisations retain ownership of activities and processes that will add to the competitive advantage of the organisation.

- Shared services is not the re-engineering of existing business and support processes without considering the context of the larger business processes they support. If the re-engineered services or processes are not aligned with the larger business processes, it will not add value and synergy but rather add conflict.

- Shared services is not an excuse for the retrenchment of employees. According to Gunn et al. (1993:24), consolidation activities have lowered employment by 30\%. Figure 5 demonstrates the reduction in head count, while enhancing business value. Although shared services will lead to "job losses" as duplication of processes are eliminated (Van Denburg et al., 2000:4), those that remain must undergo a culture change to add value and customer satisfaction, rather than merely "doing a job".

Figure 5: Shared services head count

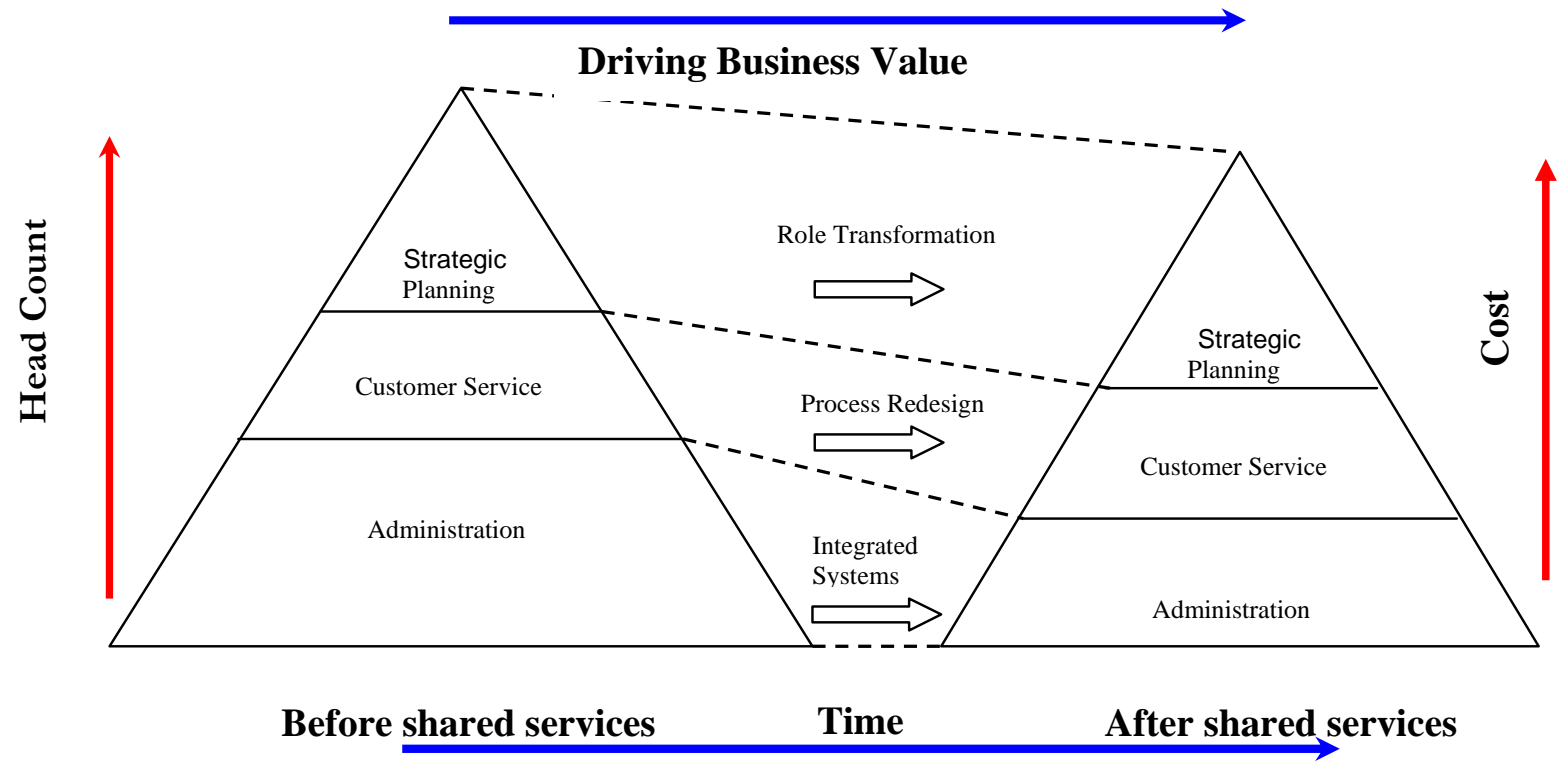

Source: adapted from Madden (2001:4)

- $\quad$ Shared services is not limited to transaction-based activities. According to Shah (1998:3), shared services begins with transaction-based processes, but eventually evolves to include professional services. Figure 6 indicates the evolution of a human resources shared services model, the reduction of transactional workload over time, with a subsequent increase in professional services over the same time period. 


\section{Figure 6: Evolution of a human resources shared services}

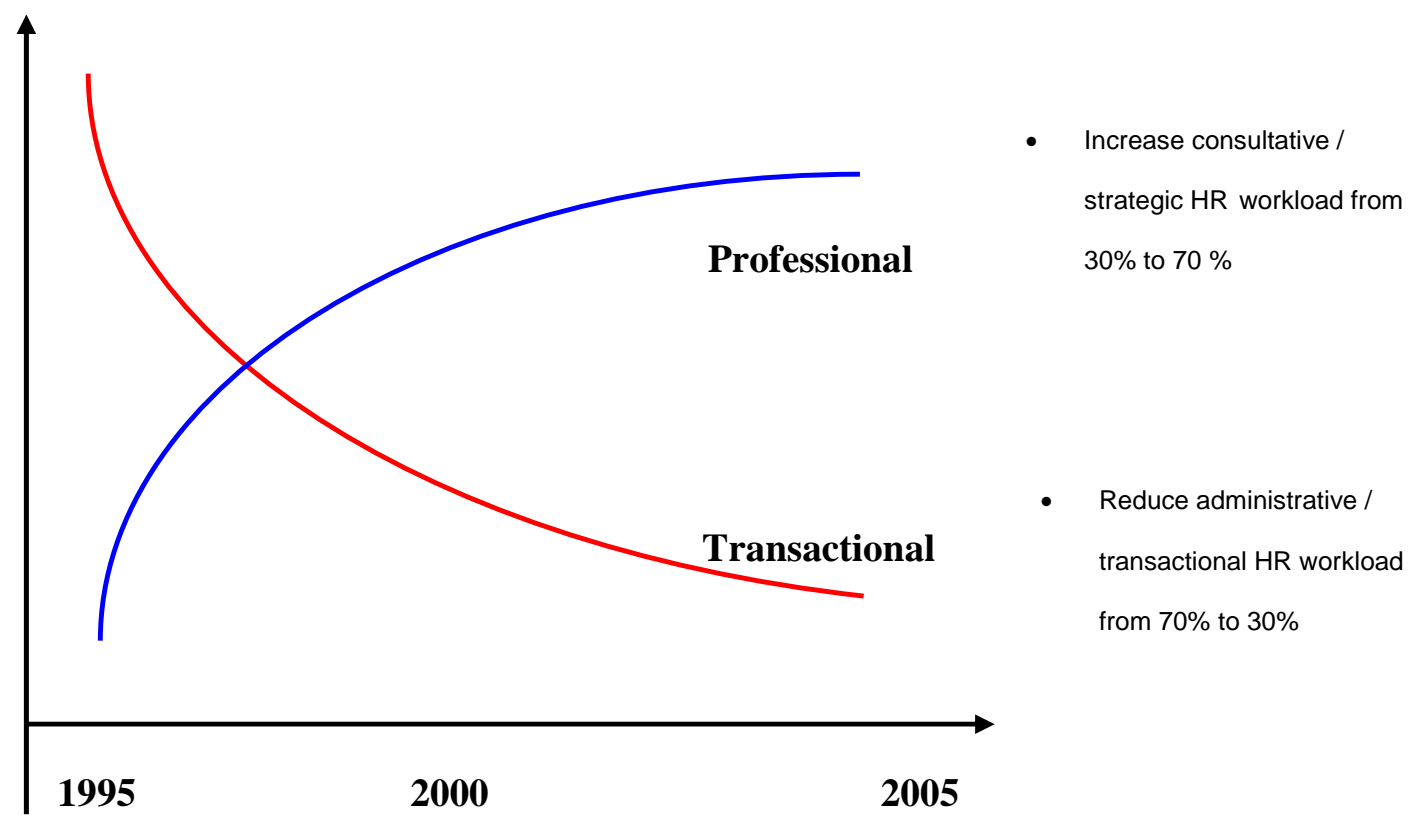

Source: adapted from Skerry (2001:6)

The above discussion can be summarised by stating that a shared services business unit is not a static entity, but rather a system that is continuously improving and re-inventing itself through continuous benchmarking, best practises, re-engineering and the use of leading edge enabling technology.

\section{WHY SHARED SERVICES?}

According to Schulman et al. (1999:27), the compelling reason for moving to a shared services environment is simple: "Customers and the business environment are demanding it". The compelling reasons for moving to a shared services business environment include:

- Globalisation. Organisations must combine information from multiple business entities across the globe. According to Schulman et al. (1999:28), the European Community (EU) is the trendsetter in a borderless global society where there is a single currency, no tariff barriers and goods are moving freely between countries. Transactional efficiency and support process effectiveness are increasingly important in the global environment as practised by global corporations. IBM's human resource centre services 305,000 employees from three service centres (Theaker, 2001:31).

- Complex organisational arrangements. "Global alliances, acquisitions, joint ventures and competitors have resulted in companies simultaneously assuming the role of customer, vendor, competitor and distributor" (Uhlrich, 1995:2). To meet these demands, the shared services organisation offers both application (technical and other functional knowledge) and specialisation (business knowledge).

- Flexible and dynamic organisations. In traditional organisations (centralised or decentralised), separate staffing departments find it difficult to shift resources quickly to meet disparate resource needs. With a shared services staff function, resources can be shifted quickly to meet business needs (Uhlrich, 1995:3). A question that can now be posed is: "What exactly is meant by it?" In the "old" economy, organisations were fragmented. Most organisations were built, marketed and sold on a national basis. In the "new" economy, time delays in business across the globe fall by the wayside. With the event of the Internet and information technology developments, business is 
a "click" away. Consumers and organisations shop globally for best purchase prices. Currency differentials will influence cost effectiveness. Within trading blocks (European Union, Southern African Development Community, etc.), tariffs and tax rates will be harmonised. "In this new world, customer profitability analysis will have to have a wider focus" (Schulman et al., 1999:28).

- Service has become a given for any organisation. One of AT\&T's shared services goals is "not to skip a beat in customer satisfaction" (Uhlrich, 1995:2). Shared services increases the quality and timeliness of services to the customer.

- Measuring what matters through shared services. As investors require more information and transparency, performance measures become more important. Through shared services, reliable performance measures can be communicated to shareholders and the investment community (Shah, 1998:9).

\section{BENEFITS ATTRIBUTED TO A SHARED SERVICES BUSINESS MODEL}

Organisations that have implemented shared services are constantly reaping tangible and intangible benefits that go beyond cost cutting and head count.

Tangible benefits include:

- Cost savings. Cost savings through shared services centres can be in the order of $30 \%$, sometimes more, depending on how far-reaching the objectives are (Lester, 2001:1). Van der Linde (2002:61) reported that all of the respondents interviewed place "cost savings" as the major reason for implementing shared services. Cost savings must go together with an increase in performance, effectiveness and efficiency (Quinn et al., 2000:3).

- Creating working capital improvements. According to Schulman et al. (1999:16), working capital improvements are gained from standardising, concentrating and netting treasury activities, operating receivables, payables, and inventory management in a centre of excellence. This creates economies of scale, improves control and decreases expenses.

- Shared services increases productivity. This involves accomplishing more with the same or less. Alcoa Business Support Services had been processing 7000 envelopes per month with twelve employees. The addition of Alumax raised the total of processed envelopes to 11000 per month with the addition of one employee (Forst, 2001:2).

- Corporate governance and professional services. Shared services business units liberate governance functions from transactional functions, as well as professional staff from transactional processes. This means they can focus on what they are supposed to do - i.e. to provide professional services to the organisation and executive team (Quinn et al., 2000:110).

- Shared services enhance corporate value. Through process re-engineering, benchmarking and the use of best practises, cost savings are achieved that add value to the organisation.

- Consolidate the transactions of common customers and vendors who deal with more than one company or business unit. According to Schulman et al. (1999:16), economies of scale are achieved through the standardisation of processes that are experienced by customers.

Intangible benefits gained from moving to a shared services environment include:

- Shared services create motivated teams to provide consistent, reliable and cost effective support. Quinn et al. (2000:124) are of the opinion that, because shared services rely on a team principle and the empowerment of employees to make decisions, it creates motivated teams that provide a consistent reliable cost effective service.

- Shared services conduct relationships with (originally) internal and external customers. Technology as well as qualified and multilingual staff, enables a shared services business unit to 
conduct relationships with local, regional and global entities such as banks, governments and suppliers (Shah, 1998:2).

- Promoting the "one company" approach. According to Schulman et al. (1999:17), this can be observed internally by employees that feel if they are members of one organisation, and externally by customers that see the organisation as a single entity.

- Shared services drives transformation more easily. According to Uhlrich (1995:8), employees still have a boundary mindset about functions and functionality. These boundaries create hurdles in service delivery. Shared services remove these boundaries by creating a common goal. From doing a "job" to "adding value".

- Shared services enhances knowledge management. Members in a shared services team share expertise (knowledge management), solve problems and add value through process reengineering. This enhances team knowledge and, according to Uhlrich (1995:13), it creates a new set of competencies and roles within the organisation.

Some organisations jump onto the shared services bandwagon because it is "faddish". According to Schulman et al. (1999:17), these organisations will achieve some of the intangible benefits, but not really any of the tangible benefits. The reasons and benefits, both tangible and intangible, provide ample reason for organisations to pursue a shared service business environment and use it as a business model to add value, and not merely to be "faddish".

\section{KEY SUCCESS FACTORS FOR THE IMPLEMENTATION OF SHARED SERVICES}

Essential in the transformation from a support service to a shared services business is the transformation of the people employed in the shared services business unit, the transformation of technology, and the transformation of business processes.

\section{Transformation of People}

According to Shah (1998:6), shared services requires the transformation of people. In centralised or de-centralised organisations, employees have a departmental relationship with other business units or organisational structures. In a shared services environment, a customer relationship must be developed. Through training and reward systems based on performance, performance measurement and performance management employees must be encouraged to act according to the values of the shared services business unit. A shared services business unit operates on a team basis, and as such has less promotional opportunities. This requires a shared services organisation to have a compensation system by which performance and the development of new skills are rewarded. Figure 7 represents the transformation that people must undergo to fit in with and support the shared services business unit.

Figure 7: People Transformation

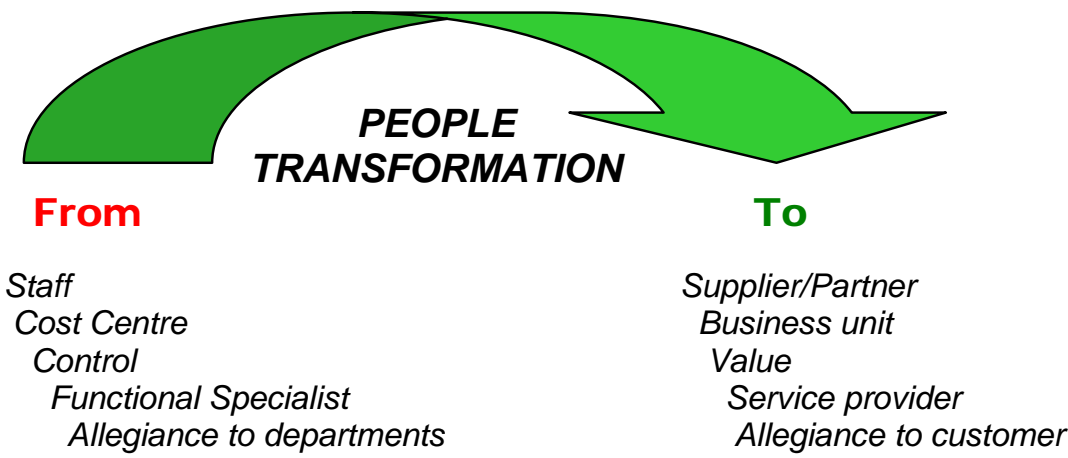

Source: adapted from Shah (1998:6) 


\section{Transformation of Business Processes}

Business process improvement often occurs on an individual basis and is not shared throughout the organisation. A move to a shared services business unit will involve a review of current processes and the design of new processes aimed at value delivery. Figure 8 represents the transformation that business processes in an organisation must undergo to move to value delivery shared services.

Figure 8: Business process transformation

- Processes not aligned with business needs.

- Processes, products and service costs not well defined.

- Redundant, fragmented and unique processes
- Processes designed to deliver value based on business needs

- Process orientation with product / service knowledge.

- Common processes and leading practises.

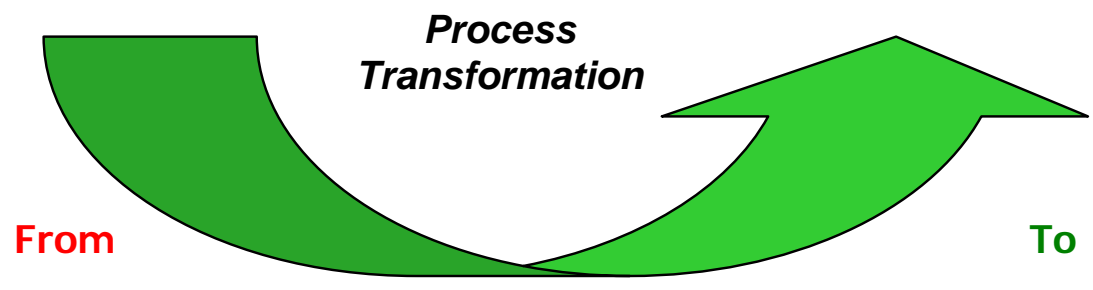

Source: adapted from Shah (1998:7)

\section{Transformation of Technology}

Historically, business units and companies within a single organisation have had independent financial, human resources management and payroll software, as well as different charts of accounts, and technology infrastructure. This independence creates silos of information that cannot be shared across the organisation. The transition to shared services requires an evaluation of all systems, business procedures and information technology infrastructure. The current technology infrastructure may not even be able to support a shared services environment. The integration to a shared services business unit is almost always a follow-up from a move to enterprise resource planning (ERP) software. Figure 9 presents the transformation that technology must undergo to successfully support the transformation to a shared services business environment.

The transformation to a shared services environment requires that the current state should continuously be monitored and compared with the "past" and the desired future state. Shah (1998:9) is also of the opinion that "Corporate performance measures become more important than ever". Through shared services, data that can be integrated, the timeliness, reliability and quality of performance measurement can now be communicated to all stakeholders. 
Figure 9: Technology transformation

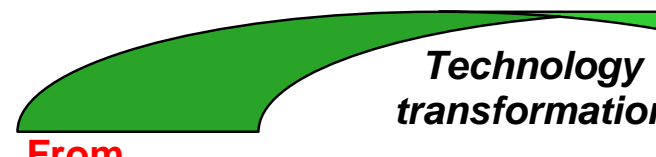

From

- Applications not integrated

- Not aligned with business processes

- Modifications extensive and costly

- Information inconsistent

- Lack of integrity (multiple sources)

- Multiple charts of accounts

- Not timely

- Mainframe or client server

- Multiple operating environments

- Technology strategy not evident

\section{Source: adapted from Shah (1998:7)}

\section{MANAGERIAL RECOMMENDATIONS}

Shared services is a viable business model that can be used by organisations to reduce costs and enhance efficiency and effectiveness. Before venturing into a shared services business model, and to garner both the tangible and intangible benefits that can be ascribed to shared services, management must ensure that:

- There is an understanding of what shared services is;

- Shared services is not used as a disguise for centralisation;

- People transformation can take place;

- Technology transformation can take place;

- Business process transformation can take place;

- All stakeholders must support shared services as a viable business proposition.

\section{CONCLUSION}

Shared services is the "commonisation" of support processes throughout an organisation. This "commonisation" is not centralisation nor de-centralisation, but includes elements of both. Centralisation focuses support operations upwards towards corporate headquarters. De-centralisation is associated with duplication of cost, effort and variable standards.

Shared services is tactical by nature and aims to support the organisation's strategy through the consolidation of support activities into a business unit that operates on business principles. Shared services focuses on value creation, and the leveraging of the skills and knowledge in an organisation. Shared services uses leading edge technology and continuously benchmarks itself against industry (and across industry) best practises. Shared services is a process of continuous improvement. Shared services is not a simple cost reduction measure, or an excuse to retrench employees. The successful transformation to a shared services business unit requires the transformation of the employees (people), business processes, and technology. Without the required transformation, shared services will remain "faddish", and the organisation will not gain the tangible and intangible benefits associated with shared services. 
Now that the concept of shared services as a "value-adding" business model has been introduced; the second article in the trilogy will explore the implementation of shared services in an organisation, as well as the various models of shared services through which an organisation can and must evolve to achieve the full organisational value that can be created by the shared services business model.

\section{REFERENCES}

Deloitte Consulting Consulting. 2000. 1999 Global shared services survey results. Unpublished

Deloitte Consulting Consulting. 2004. 2003 Global shared services survey results. Unpublished

Del Rosario JG. 2001. On the leading edge: centralization vs. shared services. Business World (Philippines) January 24 [Online] Available from: http://infotrac.london.galegroup.com/itweb/rau

Forst LI. 2001. Shared services: a leg up on acquisition payoffs. Business Europe, 41(8) April [Online] Available from: EBSCOHost: Business Source Premier: http://search.global.epnet.com

Gunn RW, Carberry DP, Frigo R \& Behrens S. 1993. Shared services: major companies are reengineering their accounting functions. Management Accounting (USA), November (75) [Online] Available from: $\underline{\text { http://infotrac.london.galegroup.com/itweb/rau }}$

Kaplan RS \& Norton DP. 1996. Translating strategy into action. The balanced scorecard. Boston: Harvard Business School Press

Lester T. (2001). Shared services: how to pool resources via the web. The Financial Times. May 11, [On-line] Internet: http://www.infotrac.london.galegroup/itweb/rau

Madden G. 2001. Reducing transaction processing costs in Cadbury Scweppes. Cadbury Schweppes. Paper presented at the shared services for the HR function conference. $24^{\text {th }}-25^{\text {th }}$ September 2001. One Whitehall Place: London.

Mohan S. 2006. Making the case for shared services in the public sector. Accountancy Ireland, August 38(4) [Online] Available from: EBSCOHost: Business Source Premier: http://search.global.epnet.com

Porter ME. 1985. Competitive advantage. Creating and sustaining superior performance. New York: The Free Press

Quinn B, Cooke R \& Kris A. 2000. Shared services: mining for corporate gold. London: Pearson Education Limited (Financial Times - Prentice Hall).

Schulman DS, Harmer MJ, Dunleavy JR \& Lusk JS. 1999. Shared services: adding value to business units. New York: John Wiley \& Sons .

Shah B. 1998. Shared services: is it for you? Industrial Management, Sept-Oct [Online] Available from: http://infotrac.london.galegroup.com/itweb/rau

Skerry J. 2001. Access the capabilities of new technologies to adopt the e-HR shared services business model. Ford Europe. Paper presented at the shared services for the HR function conference. $24^{\text {th }}-25^{\text {th }}$ September 2001. One Whitehall Place. London.

Theaker M. 2001. Implementing the self service culture: moving from manual processing to the ebusiness world. IBM Global Services. Paper presented at the shared services for the HR function conference. $24^{\text {th }}-25^{\text {th }}$ September 2001. One Whitehall Place. London.

Uhlrich D. 1995. Shared services: from vogue to value. Human Resource Planning, September 18(3) [Online] Available from: http://infotrac.london.galegroup.com/itweb/rau 
Van Denburg E \& Cagna D. 2000: Doing more with less. Electric Perspectives, January/February 25(1) [Online] Available from: EBSCOHost: Business Source Premier: http://search.global.epnet.com

Van der Linde TN. 2002. Key success factors in the management of shared services. Unpublished M.Com dissertation. Johannesburg: Rand Afrikaans University 